\title{
TRAYECTORIAS PERSONALES DE LOS EMPRENDIMIENTOS LABORALES DE INMIGRADOS CHILENOS EN ALMERÍA (ESPAÑ̃)*
}

\author{
PERSONAL TRAJECTORIES OF ENTREPRENEURSHIPS \\ OF CHILEAN IMMIGRANTS IN ALMERIA (SPAIN)
}

\author{
Pablo Hormazábal Saavedra**, Francisco Checa y Olmos ${ }^{* * *}$ y Susan Sanhueza Henríquez.***
}

\begin{abstract}
El emprendimiento puede ser una fuente de movilidad social colectiva e individual para los inmigrados. En este contexto, el artículo tiene como objetivos describir aspectos sociodemográficos y económicos de emprendedores chilenos en la provincia de Almería (España), describiendo las particularidades de las labores y negocios que desarrollan. Igualmente, exploramos las motivaciones que tuvieron para integrarse al mercado laboral por cuenta propia, así como las facilidades y obstáculos que han debido sortear para emprender sus negocios. Adoptamos un enfoque de complementariedad metodológica con el uso de cuestionarios y entrevistas en profundidad, donde participaron diez mujeres y cinco hombres que emigraron desde Chile hacia España. Los resultados demuestran la incidencia de trabajos autónomos de tipo familiar que habían sido desarrollados inicialmente en Chile, son determinantes para el emprendimiento posterior en España. Los negocios se desarrollan principalmente en el área de venta de servicios a personas y empresas, siendo las mujeres quienes mayoritariamente deciden emprender. Las motivaciones para hacerlo son diversas, sin embargo, todas ellas coinciden es que son una respuesta a la búsqueda de estrategias de adaptación económica a su nuevo entorno.
\end{abstract}

Palabras claves: Emprendimiento, inmigración, negocios, trabajo, Chile.

Entrepreneurship can be a source of collective and individual social mobility for immigrants. In this context, the article aims to describe the socio-demographic and economic aspects of Chilean immigrant entrepreneurs in the province of Almeria (Spain), describing the particularities of their entrepreneurship. Likewise, we explored the motivations that they had when integrating the working market on their own, and the facilities and obstacles that they had to overcome to start their businesses. We adopted a methodological complementarity approach with questionnaires and in-depth interviews, where ten women and five men who emigrated from Chile to Spain participated. The results show that the incidence of self-employment in Chile is a determinant of starting a business in Spain. Entrepreneurship is mainly carried out in selling services to people and companies, women being more inclined to become entrepreneurs. The motivations to do so are diverse however, they all involve searching for strategies of economic adaptation to their new environment.

Key words: Entrepreneurship, immigration, business, work, Chile.

\section{Introducción}

La inmigración internacional hace referencia al movimiento de personas que dejan su país de origen o en el que tienen residencia habitual, para establecerse temporal o permanentemente en otro país distinto al suyo. Para ello, como sabemos, estas personas han debido atravesar al menos una frontera. En este estudio nos fijamos de manera especial en el migrante económico, es decir, en esas personas que habiendo dejado su lugar de residencia o domicilio habitual buscan mejorar su nivel de vida, y el de los suyos, en un país diferente.

\footnotetext{
* El trabajo de campo base para la realización de este trabajo se ha realizado gracias a la financiación de dos proyectos: FONDECYT No 1180993, 1181531, 1191045 y al proyecto REDES, № 170039 (ambos financiados por la Comisión Nacional de Investigación Científica y Tecnológica de Chile).

** Universidad Católica del Maule, Facultad de Ciencias Sociales y Económicas. Talca, Chile. Correo electrónico: phormaza@ucm.cl. Dirección postal: Avenida San Miguel 3605, Talca.

*** Universidad de Almería, Departamento de Geografía, Historia y Humanidades, CEMyRI. Almería, España. Correo electrónico: fcheca@ual.es. Dirección Postal: Carretera Sacramento s/n 04120, La Cañada de San Urbano, Almería.

**** Universidad de Chile, Facultad de Ciencias Sociales, Departamento de Educación. Santiago, Chile. Correo electrónico: susan.sanhueza@uchile.cl
} 


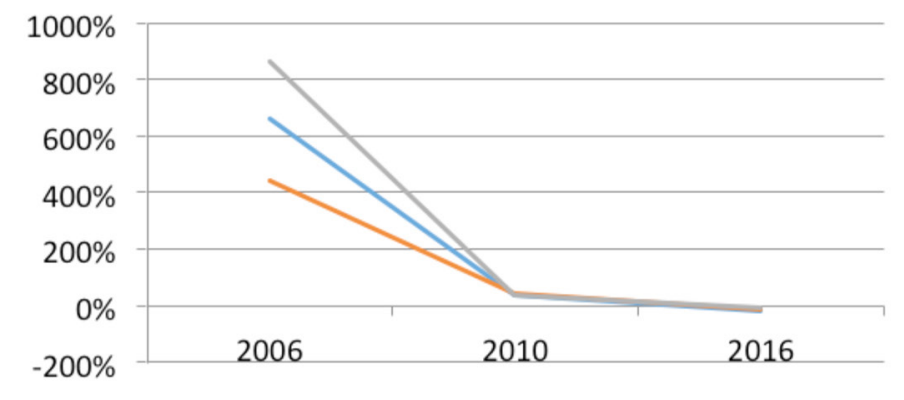

Crecimiento porcentual de Extranjeros

Poblc. Extranjeros en España

Poblc. Extranjeros en

Andalucía

Poblc. Extranjeros en

Alamería

Figura 1. Crecimiento porcentual de extranjeros en España.

Fuente: Instituto Nacional de Estadística (INE). www.ine.es. Elaboración propia.

Se estima que en el mundo hay 232 millones de migrantes internacionales, concentrados fundamentalmente en diez países muy urbanizados y con altos ingresos, como Estados Unidos de América, Canadá y Australia, así como varios países europeos, Alemania, Reino Unido, Francia y España (ver Figura 1).

Como se observa en la Figura 1, tras la crisis económica iniciada en 2008, la migración hacia España ha disminuido, pero aún hoy sigue siendo muy importante, ya que, con datos del INE, en 2016 alcanzaba las 4.618 .581 personas, a mediados de 2018 frisaba nuevamente casi los cinco millones (4.719.418).

Desde el 2000, España ha sido un destino atractivo para los migrantes latinoamericanos, quienes representan casi 5\% de la población española. En su punto álgido, antes de 2008, más de 2,4 millones de migrantes de origen latinoamericano residían en España.

Los migrantes latinoamericanos, como el resto de africanos o europeos del este, a menudo dependen de empleos de baja remuneración: trabajo doméstico y cuidado de personas mayores, labores de limpieza en bares y restaurantes, para las mujeres, o agricultura y construcción para los varones, que reportan tasas de ahorro muy bajas, sabiendo que han de hacer frente a gastos muy diversos, empezando por los alquileres de viviendas.

Aun así, $86 \%$ de los inmigrados latinoamericanos residentes en España posee cuentas bancarias, pero tan solo el $32 \%$ usó una cuenta bancaria para ahorrar. Estos migrantes también exhiben menores tasas de propiedad de activos, solamente $12 \%$ posee una casa en España, comparado con $78 \%$ entre la población general.

En este artículo abordamos la migración chilena que vive en España. En total para 2016 había una población chilena en España que alcanzan las 25.407 personas, lo que viene a suponer casi el uno por ciento de la población migrante total (ver Figura 2). La tendencia es bajista, pues a finales de 2018 se registraban 23.365, unas dos mil personas menos.

Hace casi una década que L. Wong y $\mathrm{H}$. Primecz (2011) señalaban que el rápido aumento de la inmigración internacional en los países desarrollados y su contribución al crecimiento económico y el desarrollo regional, habían dado lugar a una gran cantidad de estudios respecto de su participación en los mercados de trabajo, no solo como empleados, sino más bien como emprendedores y (normalmente pequeños) empresarios.

Es conocido que la pasada crisis financiera y económica vivida a nivel mundial ha tenido consecuencias devastadoras para muchísimas economías y, por tanto, familias. Entre los diferentes efectos adversos ocasionados se encuentra la vulnerabilidad a la que se ven sometidos determinados colectivos, en especial los inmigrados. Ahora bien, incluso dentro de este contexto desfavorable, aquellos inmigrados que han decidido desarrollar iniciativas emprendedoras, identificando alguna oportunidad de negocio para convertirla en una realidad viable, se están convirtiendo en un colectivo que facilita en última instancia la revitalización de la economía (véanse Achidi y Priem, 2011; Chand y Ghorbani, 2011). 


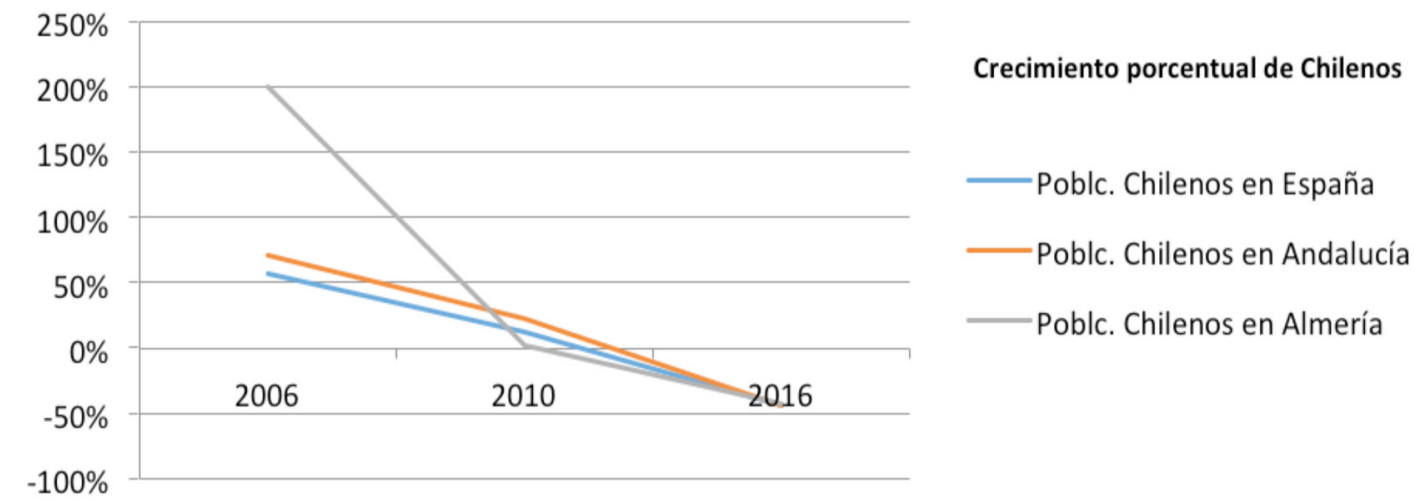

Figura 2. Crecimiento porcentual de chilenos en España.

Fuente: Instituto Nacional de Estadística (INE). www.ine.es. Elaboración propia.

\section{Emprender para integrarse socialmente}

El emprendimiento inmigrante internacional define a los inmigrantes emprendedores como personas que, recién llegados a un país, inician un negocio como medio de supervivencia económica (Chaganti y Greene, 2002). Además, un inmigrante es una persona que ha estado fuera de su país de origen durante al menos 12 meses (Sasse y Thielemann, 2005).

La creación de nuevos puestos de trabajo, la introducción de nuevos productos en el mercado y la generación de competencia son algunos de los aspectos positivos del emprendimiento económico que realizan migrantes en los países de destino. Ellos están dispuestos a asumir riesgos y a enfrentar cambios, llegan a ser creativos, independientes y dinámicos (entre otras cualidades), ya que ven en esta actividad una forma de mejorar su estilo de vida y de obtener una fuente de ingresos. Es un cálculo en su proyecto migratorio de los riesgos y beneficios que pueden alcanzar a corto y medio plazo (Checa, 1995). En efecto, quienes han emprendido un nuevo negocio acceden a nuevas oportunidades laborales e incluso les brinda la oportunidad de percibir ganancias salariales superiores a las del trabajo por cuenta ajena (Constant y Shachmurove, 2006).

Hoy se considera que el emprendimiento es una estrategia de desarrollo, aunque no todas las iniciativas de crear pequeños negocios aporten de igual manera a ese objetivo. Según Newland y Tanaka (2010), existen emprendimientos "por necesidad" y otros "por oportunidad". Los primeros son resultado de situaciones de desempleo y contribuyen al sostén económico, e incluso a la reducción del desempleo abierto, pero en realidad impulsan muy poco el desarrollo económico del lugar. Los emprendimientos por necesidad tienen más probabilidad de contribuir a ese desarrollo, ya que pueden aprovechar las oportunidades que se presenten e introducirse mejor en los canales comerciales o de explotación.

En realidad, como señalan Tovar y Victoria (2013), el éxito de las actividades de emprendimiento depende del entorno económico, cultural, político e institucional en el que se desarrollan. Les favorece una economía fuerte y estable, un acervo adecuado de capital humano y social, un ambiente institucional de alta calidad y el fácil acceso a la financiación. La manera de percibir culturalmente al emprendedor se puede volver atractivo o no convertirse en uno de ellos, así como las políticas gubernamentales también pueden fomentar u obstaculizar la creación de pequeños negocios. Estos autores además agregan que cada cual adopta su propia definición de emprendedor. En algunos, el emprendedor es quien crea o registra un pequeño negocio. En otros, es un empleador, un autoempleado o quien tiene un proyecto de negocio adicional a su actividad económica usual.

Muy poco se ha dicho acerca de las problemáticas que enfrentan migrantes al emprender, por ejemplo, cómo afectan las medidas de protección de los gobiernos para proteger sus mercados laborales nacionales o cómo discriminan positivamente los instrumentos públicos a los migrantes 
para el acceso a financiamiento para emprender (véanse Arjona, 2004; Arjona, Checa y otros, 2007). Ya Raijman y Tienda (2003) señalaron que cualquier inmigrante tiene ciertas desventajas a la hora de convertirse en un emprendedor. Como hemos visto, se topará con limitaciones debido a diferencias de cultura, a las experiencias entre el país de origen y el país receptor, así como al grado de conocimiento que atesore de la cultura del país de instalación.

Ahora bien, independientemente de los obstáculos que va a encontrar, lo cierto es que el autoempleo a menudo es considerado como un aspecto importante en la integración económica de los inmigrantes en el país de acogida. Algunos de ellos se involucran en el trabajo por cuenta propia con el fin de superar las limitadas oportunidades de empleo y los bajos rendimientos a las habilidades que poseen y que han sido adquiridas en el extranjero (Fairlie y Meyer, 1996), mientras que otros entran en el autoempleo como una forma de poner en práctica sus ideas de negocio, ganar flexibilidad laboral y buscar ingresos más altos: "trabajo para mí mismo", se nos repetía durante el trabajo de campo (Wang, 2011).

Por otra parte, uno de los aspectos más valorados desde el emprendimiento o el autoempleo es la generación de nuevos puestos de trabajo, ya que los migrantes autónomos suelen ser empleadores de otros compatriotas (en la mayoría personas con menos cualificación) y de autóctonos que se encuentran desempleados (Yuengert, 1995).

Como se puede observar, existe un acuerdo de lo beneficioso que suele llegar a ser el emprendimiento de migrantes en los países de acogida y las ventajas que conlleva; sin embargo, es curioso la escasa información que existe respecto de las condiciones en que lo hacen, las dificultades que atraviesan y el impacto que estos emprendimientos tienen para la economía local. Aún hoy existen escasas evidencias de la relación existente entre emprendimiento y la integración/movilidad social.

A partir de lo expuesto, en el presente trabajo estamos interesados en, primero, describir aspectos sociodemográficos y económicos de las colonias de inmigrados chilenos en la provincia de Almería (España), como elementos que configuran las condiciones en las que se integran socialmente a la sociedad receptora. Segundo, analizar la inserción dentro del mercado laboral -por cuenta propia- de los chilenos residentes en España, describiendo las particularidades de los emprendimientos que desarrollan y las implicancias en el mejoramiento de la calidad de vida que poseen. Por último, determinar las motivaciones de estos chilenos en España, para integrarse al mercado laboral por cuenta propia, identificando facilidades y obstáculos que han debido sortear para emprender sus negocios.

\section{Método}

\section{Enfoque y diseño}

Optamos por un pluralismo epistemológico que Arias (2012) define como el uso de los métodos cuantitativo y cualitativo para abordar un único fenómeno de investigación. En particular, se empleó una aproximación deductiva (de lo cuantitativo a lo cualitativo) donde una comprensión más hermenéutica del fenómeno permite abordar eventos inesperados hacia el final de la investigación (Sanhueza, Friz y Quintriqueo, 2017).

En particular, para describir aspectos sociodemográficos y económicos de las colonias de migrantes chilenos en la provincia de Almería y su integración al mercado laboral por cuenta propia, empleamos un diseño no experimental de tipo descriptivo, con uso de un cuestionario, mientras que para aproximarnos a sus motivaciones como emprendedores empleamos un diseño de estudios de casos mediante entrevistas y relatos de vida (Checa, Checa y Arjona, 2002).

\section{Contexto y participantes}

La investigación se llevó a cabo en la provincia de Almería, perteneciente a la Comunidad Autónoma de Andalucía, situada en el sureste de la península ibérica. Según el INE (2016), la población total provincial es de 704.297, con una ligera predominancia de hombres sobre las mujeres. Las actividades productivas son diversas, no obstante, destacan la agricultura, el turismo, la industria del mármol y la piedra natural, entre otros. El número de chilenos en Almería alcanzó a las 212 personas durante el 2016 (ver Figura 3).

Como se puede observar, si bien el crecimiento porcentual se detuvo el 2016, el número de chilenos que reside en Almería continúa siendo destacable. 


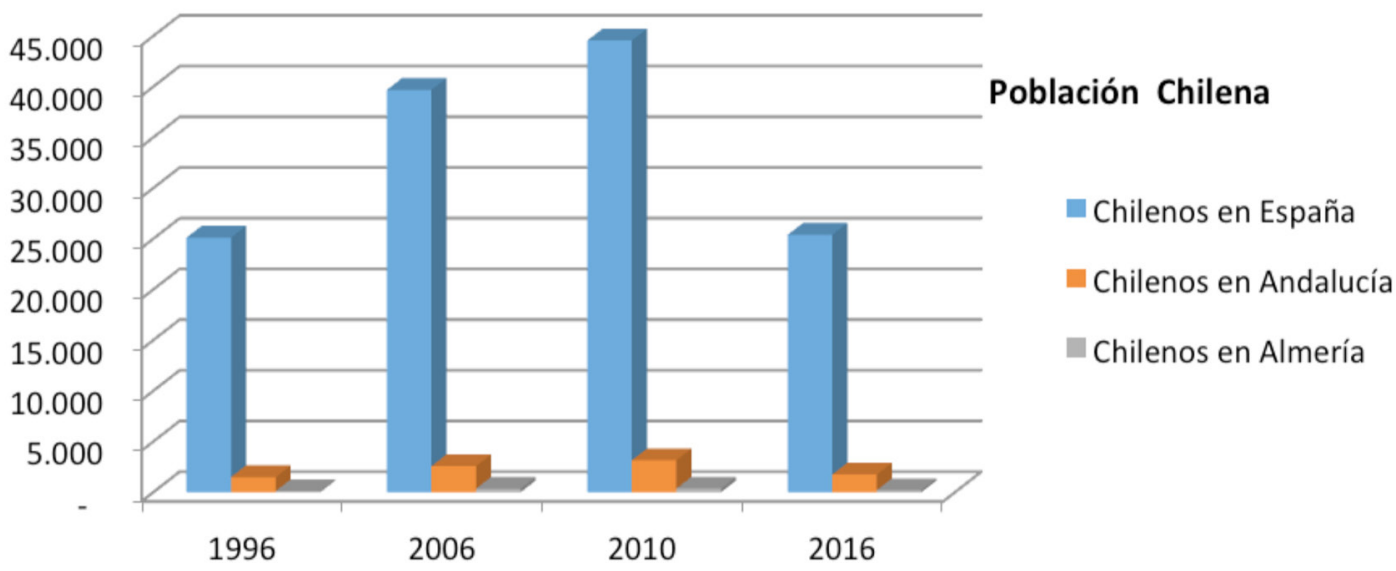

Figura 3. Chilenos residentes en España.

Fuente: Instituto Nacional de Estadística (INE). www.ine.es. Elaboración propia.

Como el propio título del artículo indica, la población objeto de estudio fueron los inmigrados chilenos que residen en Almería y, al mismo tiempo, emprendedores dedicados a una actividad comercial o negocio por cuenta propia, cuya actividad desarrollada puede estar en cualquier tipo de industria, o bien un profesional independiente que preste sus servicios por cuenta propia, con o sin oficina establecida.

Optamos por una muestra no probabilística, es decir, definida a conveniencia del investigador (Cornejo, Sanhueza y Rioseco, 2012), siguiendo pautas como: según contactos encontrados en redes sociales, referidos por otros inmigrados de los colectivos objeto de estudio, por ubicación y conocimiento de los negocios establecidos, o bien por contactos de agrupaciones y asociaciones de inmigrantes chilenos o afines, amén de otras referencias.

La muestra quedó conformada por 15 chilenos (10 mujeres y 5 hombres), cuyas edades fluctuaban entre 25 y 67 años, con un promedio de residencia en España de 14 años. Como se puede observar en la Tabla 1, la mayoría de los participantes emprenden sus negocios en el ámbito de las empresas orientadas a dar servicio a las personas y en empresas de restauración (restaurantes, cafeterías y bares).

\section{Técnicas de recolección de la información}

Para aproximarnos a estas cuestiones empleamos un cuestionario denominado Integración
Socioeconómica para Inmigrantes Emprendedores (ISIE), validado por A. Arjona (2004) en la provincia de Almería, en su estudio acerca del mercado étnico. Consta de 60 preguntas de respuesta múltiple. El instrumento se organiza en 5 grandes apartados.

El primer apartado, Datos sociodemográficos, tiene 10 preguntas, donde se consultan aspectos como edad, género, permanencia en el país, lugar de procedencia, estudios, situación familiar.

El segundo apartado, Trayectoria laboral, incluye preguntas de cómo emprendió su negocio, origen del emprendimiento, recursos con los que contó al momento de iniciar el negocio, etc., con un total de 19 preguntas.

En el tercer apartado, Características de la empresa y actividad, mediante sus 13 preguntas se consultan aspectos como el número de trabajadores de la empresa, procedencia de sus productos, clientes, facturación, gastos, facilidades y obstáculos para emprender.

El cuarto apartado, Percepción sobre el contexto en el cual se emprende, lo forman 8 preguntas para conocer aspectos de discriminación, condiciones en que debe darse un emprendimiento, percepción de los autóctonos respecto del autoempleo de los inmigrados, la proyección de nuevos emprendimientos, etcétera.

Por último, un quinto apartado concerniente a Ubicación espacial de la actividad, donde, por medio de 10 ítems, se especifica una descripción del interior y exterior del negocio, la superficie, la forma de acceso y cercanía de negocios similares, etc. 
Tabla 1. La muestra.

\begin{tabular}{|c|c|c|c|c|c|}
\hline Nombre & Edad & Actividad & $\begin{array}{l}\text { Permanencia en España } \\
\text { (en años) }\end{array}$ & Nivel educativo & $\mathrm{N}^{\mathrm{o}}$ de hijos \\
\hline Ángela & 46 & Corredor de propiedades & 11 & Técnica & 2 \\
\hline Laura & 33 & Cafetería & 13 & Secundaria & 3 \\
\hline Pamela & 48 & Cuidado de adultos & 16 & Universitaria & 3 \\
\hline Víctor & 35 & Locutorio & 15 & Secundaria & 2 \\
\hline Carlos & 44 & Cafetería & 12 & Secundaria & 3 \\
\hline Eduardo & 36 & Cafetería & 11 & Técnica & 0 \\
\hline Cecilia & 62 & Corredor de propiedades & 14 & Universitaria & 4 \\
\hline Carolina & 43 & Restaurante & 18 & Postgrado & 0 \\
\hline Marcela & 43 & Clases de baile & 19 & Universitaria & 1 \\
\hline Martín & 31 & Servicios de limpieza & 15 & Secundaria & 1 \\
\hline Nathalie & 25 & Comercio & 9 & Secundaria & 1 \\
\hline Diego & 27 & Clases de pádel & 12 & Universitaria & 0 \\
\hline Daniela & 39 & Servicios de limpieza & 13 & Técnica & 1 \\
\hline Rosa & 67 & Vendedora de joyas & 12 & Técnica & 3 \\
\hline Josefina & 28 & Tour privados & 13 & Postgrado & 0 \\
\hline
\end{tabular}

Fuente: Elaboración propia a través del trabajo de campo.

Este apartado integra adicionalmente preguntas concernientes a la participación de estos emprendedores en algún programa de ayudas y apoyo a las PYME (estatal, regional o municipal), así como el acceso a capacitaciones, ayudas para inmobiliario o préstamos para equipamiento.

En nuestra investigación, con el propósito de profundizar en aspectos relacionados con la inmigración chilena, implementamos el ISIE con otras preguntas semiestructuradas, de este calibre:

“CCómo cree que, en general, ven los españoles/chilenos este tipo de negocio en personas inmigradas?”; “Cree que seguirán llegando inmigrantes chilenos en los próximos años y, quienes vengan, en qué sectores piensa usted que se insertarán?”; “Cree que habrá más posibilidades de creación de empresas por parte de población inmigrada y qué condiciones deben darse para que tengan éxito?"; "En general, ¿cómo ve el futuro de su empresa y los trabajos de inmigrados por cuenta ajena?", ¿y del sector al que usted pertenece?

\section{Procedimiento y análisis de datos}

Los datos fueron analizados en dos fases. $\mathrm{La}$ primera incluyó la elaboración de una matriz de datos y el cálculo de medidas de tendencia central, de dispersión, frecuencias y porcentajes.

En la segunda fase se contemplan tres momentos: el primero consistió en dar visibilidad al fenómeno mediante la trascripción y lectura de las entrevistas de los 15 inmigrados que habían sido objeto de estudio, observando en qué medida se iban confirmando las categorías definidas inicialmente. A continuación empleamos etiquetas preliminares, al modo de lentes para mirar la información. Para ello se realizaron anotaciones en el margen de los textos que posteriormente consolidaron las categorías. Por último, llevamos a cabo la triangulación metodológica, tomando como base la información obtenida de los cuestionarios y entrevistas, complementada con los referentes teóricos que provienen de la literatura especializada.

Siguiendo los planteamientos de Sanhueza, Penalva y Friz (2013) se incluyó una fase relacional, donde se integran los resultados obtenidos en las fases anteriores y se establecen ideas núcleo que fueron desarrolladas con otros segmentos y justificadas con el marco conceptual de partida. Implicó un nivel más complejo de análisis, ya que por medio de un proceso inductivo los datos fueron validados y reformulados sucesivamente a lo largo del proceso. Para una mayor validación, el análisis conjunto fue comparado con las investigaciones señaladas en el marco conceptual. La información obtenida se ha ido refinando y ampliando. 


\section{Resultados}

\section{Datos sociodemográficos y económicos de los chilenos en Almería}

Los chilenos participantes en nuestro estudio en su mayoría son provenientes de Santiago, capital del país, seguidos de quienes llegaron desde la zona central costera, Valparaíso. Han permanecido en promedio 14 años en España.

Los resultados nos muestran que los emprendimientos de estos chilenos son implementados principalmente por mujeres $(n=10)$, cuyas edades oscilan entre 25 y 67 años. En un primer análisis, podemos observar que la mayoría de los emprendedores posee estudios en educación superior, ya sea a nivel técnico, universitario o postgrado (ver Tabla 2); no obstante, su formación académica no coincide con el tipo de actividad que realizan, por ejemplo, una de las mujeres con estudios universitarios se ocupa en el cuidado de adultos y otra imparte clases de baile. Las actividades que realizan los chilenos varones se concentran en cafeterías, propietario de un locutorio o impartiendo clases de pádel. En realidad, existe un correlato con aquellas ocupaciones que tradicionalmente se han atribuido a roles de género, femenino y masculino, respectivamente.

Tabla 2. Actividad, nivel educativo y género de los inmigrados chilenos emprendedores.

\begin{tabular}{cll}
\hline Género & \multicolumn{1}{c}{ Actividad } & Nivel Educativo \\
\hline M & Corredor de propiedades & Técnico \\
M & Cafetería & Secundaria \\
M & Cuidadora Adultos & Universitaria \\
H & Locutorio & Secundaria \\
H & Cafetería & Secundaria \\
H & Cafetería & Técnica \\
M & Corredor de Propiedades & Universitaria \\
M & Restaurante & Postgrado \\
M & Clases de baile & Universitaria \\
H & Servicio de limpieza & Secundaria \\
M & Comercio & Secundaria \\
H & Clases de Pádel & Universitaria \\
M & Servicio de limpieza & Técnica \\
M & Vendedora de joyas & Técnica \\
M & Tour privados & Postgrado \\
\hline
\end{tabular}

Fuente: Elaboración propia por medio del trabajo de campo.
La mayoría de quienes llegaron a Almería lo hacen acompañados de sus familias, con una historia de migración previa y con la experiencia de haber emprendido negocios en Chile. A pesar de ello, al llegar a Almería debieron trabajar por cuenta ajena para poder subsistir $(n=12)$. Las experiencias iniciales de trabajo siempre son narradas con precisión:

Una vez por vacaciones fuimos a veranear, yo tenía familia en esa zona y estuve trabajando en un "Paki", lo que es aquí un almacén, como envasadora de uva, pero fue una temporada de verano, y luego ya cuando empecé a trabajar. Siempre trabajé en comercios, dependienta de tiendas, de un club de video de alquiler de películas (Ángela, 46 años).

Cuando llegué aquí a España, pues lo primero que hice fue empezar a buscar y me encontré un trabajo de camarero, entonces empecé a trabajar a los 4 días de llegar a España, con lo cual a los 4 meses ya tenía mi tarjeta de residencia, autorizado para trabajar legalmente. Entonces no me fue tan difícil trabajar, directamente me puse a trabajar de camarero en la hostelería (Víctor, 35 años).

La mayoría de los emprendedores está establecido (60\%) y es titular de su empresa (93\%), siendo principalmente los autóctonos sus clientes habituales. Manifiestan no tener necesidad de contratar personas para trabajar en sus negocios (66\%) y señalan que la procedencia de sus productos es española. Cuando se les pregunta por sus horarios de trabajo, la mayoría reconoce no tener horario definido, lo que viene a significar que dedican muchas horas a su negocio. Una de las entrevistadas señala:

Todo el día, con el móvil, voy, vengo, busco, rebusco, llamo... Trabajo mucho, intento organizarme, intento... Entonces intento planificarme, trabajo mucho desde el ordenador en casa de noche, o sea el tiempo en el que podría estar en la oficina y estar con el ordenador, lo dejo para la noche... Por la tarde hago llamadas, veo mis emails, lo reviso... También 
sábados y domingos, porque los domingos aquí normalmente hay mercadillos en Villaricos [norte de la provincia] y va mucha gente, entonces muchas veces hacemos flallers y repartimos (Cecilia, 62 años).

El trabajo demanda esfuerzos adicionales que los chilenos están dispuestos a sobrellevar, incluso cuando se trata de vacaciones. Si bien algunos señalan tomarse algunos días, lo hacen sin desconectarse del todo del negocio. Otros simplemente no alcanzan a disfrutarlas. Uno de los participantes nos señala:

De vacaciones nada, y si hubiésemos seguido fuerte tampoco. Si tienes una empresa no puedes tener vacaciones, no puedes darte el beneficio de perder un día. Vale si te lo dicen... Oye vete de vacaciones que lo voy a pagar, pero ese hombre tiene que tener a otra persona moviendo dinero para que tú puedas irte. El dueño no puede... Tiene que tener mucho para poder tener vacaciones. El día que no trabaje es un día perdido, eso lo aprendí en EE.UU., donde estuve hace 3 meses: "no tengo ganas de ir a trabajar, pues me pido una semana de vacaciones". Cada día que no iba era un día que no ingresaba dinero y si gasto, y entonces perdía dos días. No te puedes permitir tener vacaciones siendo empresario, si quieres ganar algo... (Martín, 31 años).

Cuando se les pregunta si recibieron algún tipo de ayuda para emprender sus negocios, el $55 \%$ indica que no. De entre quienes sí tuvieron apoyos económicos, destacan aquellos que lo hacen principalmente mediante créditos financieros o de sus familias, aunque también desde algún organismo oficial, como el Ayuntamiento o por el gobierno de la Junta de Andalucía. Ninguno asegura haber recibido capacitación exprofeso, sí con asesorías externas (gestores, abogados) y valiéndose de su experiencia anterior.

Respecto del ingreso que perciben los chilenos, es posible observar diferencias significativas. En efecto, algunos chilenos han logrado generar importantes recursos para subsistir y llevar una buena calidad de vida, mientras otros reciben ingresos muy precarios que deben complementar con trabajos por cuenta ajena, habitualmente de carácter esporádico, como se observa en la Tabla 3.

Tabla 3. Ingresos de los inmigrados chilenos en Almería, por tipo de negocio.

\begin{tabular}{|c|c|c|}
\hline Actividad & $\begin{array}{l}\text { Ingreso mínimo mensual } \\
(€)\end{array}$ & $\begin{array}{l}\text { Ingreso máximo mensual } \\
(€)\end{array}$ \\
\hline Alquiler de pisos & 300 & 1.200 \\
\hline Desayunos, comidas, meriendas, cenas & 12.000 & 15.000 \\
\hline Cuidado del adulto mayor & 600 & 900 \\
\hline Internet, teléfono, tarjetas para llamar & 1.900 & 1.900 \\
\hline Restaurante & 1.000 & 4.000 \\
\hline Café & 18.000 & 20.000 \\
\hline Alquiler y venta de propiedades & 2.000 & 2.000 \\
\hline Restaurante & $\mathrm{s} / \mathrm{i}$ & $\mathrm{s} / \mathrm{i}$ \\
\hline Clases de baile & 600 & 800 \\
\hline Servicios de mantenimiento y aseo & 1.600 & 1.600 \\
\hline Desayunos & 2.000 & 2.000 \\
\hline Clases de pádel grupales e individuales & 400 & 450 \\
\hline Servicios de limpieza & 500 & 500 \\
\hline Servicio de masajes & 80 & 100 \\
\hline Servicio turístico y alquiler & 450 & 600 \\
\hline
\end{tabular}

Fuente: Elaboración propia por medio del trabajo de campo. 
Los servicios asociados a comida, como restaurantes y cafeterías, son los que generan mejores ingresos para los chilenos, con un promedio de 3.600 euros, mientras trabajos como el servicio doméstico, clases de baile o servicio de masajes, se encuentran por debajo del salario mínimo interprofesional español (unos 900 euros).

\section{Caracterización del tipo de actividad}

Las actividades por cuenta propia que realizan los chilenos pueden ser agrupadas en servicios, comercio, rubro de comida y otros (ver Tabla 4).

Algunos de nuestros informantes narran cómo antes de alcanzar la propiedad de un negocio propio debieron trabajar por cuenta ajena. En algunos casos también se han visto obligados a volver a la nómina del trabajo asalariado, habiendo tenido un negocio propio que no le funcionó como esperaba. Las razones de estos cambios hay que buscarlas, según sus respuestas, en situaciones familiares propias, como la crianza de los hijos, un divorcio o momentos de crisis. Una de las participantes nos comenta:

Cuando llego estoy dos o tres años sin trabajar para que los niños se adaptaran, porque venían más o menos pequeños, para que se adaptaran a los colegios. Y luego sí, luego pusimos una croissantería. Y cerramos esa y abrimos otra más céntrica y estuve como cinco años con ella, pero por el tema del divorcio la tuvimos que traspasar. Y ya luego empecé a trabajar cuidando personas (...). Siempre

Tabla 4. Actividades desarrolladas por emprendedores chilenos.

\begin{tabular}{lc}
\hline \multicolumn{1}{c}{ Actividades Generales } & Chilenos \\
\hline Venta de Servicios a Personas y Empresas & 6 \\
Comercio y venta de productos & 2 \\
Restaurante, cafetería y bar & 4 \\
Clases a personas y grupos & 2 \\
Construcción & 0 \\
Cuidado de adultos & 1 \\
Diversión y esparcimiento & 0 \\
\hline Total & 15 \\
\hline
\end{tabular}

Fuente: Elaboración propia a través del trabajo de campo. había querido trabajar por mi cuenta (...). Lo que pasa que ya luego no la pude retomar [la croissantería] porque económicamente me era imposible a mí sola montarla. Tenía que tener el dinero para un alquiler, pagar maquinaria... y ya me era imposible; por eso me tuve que poner a trabajar cuidando personas. Pero mi idea siempre fue trabajar como autónoma (Pamela, 48 años).

Mientras la mayoría de los participantes señala no haber recibido apoyos para emprender, algunos apuestan por la actitud emprendedora como determinante para el éxito de un negocio. Uno de los chilenos comenta:

La situación pues eso que, si tú quieres hacer algo, lo puedes hacer, que te ayudan, te ayudan, pero ¿qué tipo de ayuda estás buscando: Que te monten un negocio y que te digan "venga ya lo tienes montado, ponte a trabajar"? No es así, pero para nadie. Tienes que moverte tú, hacerlo tú; ¿que no te ayudan?, pues nada, sigue tu solo. Te frustras, ite echas a llorar?, no puedo seguir porque no me han ayudado. Así no es, sigue tú solo y lo haces, ya está, o no lo haces, ya lo que tú quieras. Pero eso, la decisión siempre es tuya. ¿Podrían ayudarte?, pues sí, por ejemplo, bajando el precio de lo que pagan los autónomos. A mí 300 euros de autónomo me parece que es mucho dinero, pero es lo que hay (Eduardo, 36 años).

Respecto de los principales clientes que tienen los emprendedores chilenos, la mayoría son españoles, aun cuando se trata de negocios turísticos o de alquiler. Con ello, los participantes consideran que aportan a la economía local. Una de las informantes explica:

Hemos empezado fuerte con los ingleses y los españoles han llegado un poco después, digamos, porque el público inglés recibe muy bien lo que es nuevo, porque la cocina propia de Inglaterra es una cocina ya de por sí fusionada. Y luego los españoles han ido viendo que, digamos 
que al final... Y luego, ahora es un momento de un poquito de cambio, porque por ejemplo en verano hemos tenido muchísimo turista español y hemos visto menos ingleses. Entonces estamos a la expectativa, sobre todo por lo que pueda producirse con el tema del Brexit (Carolina, 43 años).

La mayoría de los emprendedores reconoce los efectos contextuales que inciden en sus negocios; aspectos políticos, económicos, nuevas regulaciones, cambios en el gobierno, crisis internacional, etc. Esta situación los pone en constante incertidumbre respecto de la continuidad de sus negocios. Una de las emprendedoras que se dedica al rubro inmobiliario señala:

Claro, claro, depende de la temporalidad, depende de la economía básicamente porque esto se vino un boom. O sea, la primera afectada, fue evidentemente, el mundo inmobiliario. Hasta que vino el tema de los bancos y la gente comenzó a comprar. Pero claro depende mucho de la economía, es muy sensible. Las elecciones, por ejemplo, este año nos han pasado factura porque la gente tiene una inseguridad tremenda, la gente no se atreve, no quiere... ahora vamos a ver si con esta mini estabilidad que parece ser que hay pues que el mercado toma confianza y la gente vuelve a invertir de nuevo. Estamos sujetos a eso (Cecilia, 62 años).

Por último, son temas recurrentes en los chilenos entrevistados esas situaciones como la tecnologización del mercado, la cantidad de impuestos que deben pagar o la falta de políticas gubernamentales de acompañamiento a los emprendimientos. Frente a esta situación, les consultamos cuál sería la diferenciación del negocio frente a otros. Encontramos respuestas bastante coincidentes entre sí, que hacen referencia a una relación personalizada empresario-cliente, experiencia, eficiencia y menores costos. Uno de los chilenos señala:

Mira, este bar cuando lo hicimos no entraba nadie, estaba vacío, vacío todos los días. Pasamos un mes y seguía vacío y yo me decía: algo tenemos que hacer. Y este bar era el primero que poníamos una jarra de cerveza de medio litro más dos tapas, por 3 euros, y empezó a llenarse, a llenarse... Hubo una cosa también muy importante, además de las promociones: la buena calidad en el producto y la atención al cliente (Carlos, 44 años).

\section{Motivaciones para el emprendimiento}

Las colonias de extranjeros en cualquier país del mundo buscan integrarse a la comunidad y esta integración la realizan de variadas formas. El propósito fundamental de cada individuo es permanecer en el lugar donde se ha instalado, consiguiendo mejores condiciones de vida que las que tenía en su país de origen.

Para el logro de este objetivo, lo principal es tener un trabajo estable y bien remunerado, para que la supervivencia venga asociada a una mejora de su calidad de vida; esta va expresada o materializada en el acceso a la educación (de calidad), la adquisición de nuevas culturas, el aumento de su patrimonio mediante el ahorro, la adquisición de bienes y, en algunos casos, es muy deseable la posibilidad de remesas o retribuciones para sus familiares que permanecen en su país de origen.

Para aproximarnos a las motivaciones de los inmigrantes chilenos para emprender, podemos observar respuestas diversas, todas ellas relacionadas con sus historias de vida. Lo cierto es que la mayoría de los participantes en esta investigación indicó que siempre albergaron una idea preconcebida de conseguir un negocio propio. Una de las mujeres que montaron un bar nos señala:

Porque deja mucho dinero, más que la hostelería: no tienes cosas que caduquen o que tengas que tirar, aquí no hay mucho gasto; en la hostelería la contribución es muy alta y la luz es muy cara, por lo menos 2.000 euros. Yo en el bar, 70 euros al mes. Aunque hay diferencias, yo me tengo que tirar toda la mañana para hacer 100 euros, ellos en la mañana más mala salen con más de 300 (Laura, 33 años).

El desempleo y las dificultades para encontrar un trabajo por cuenta ajena también motivaron a 
algunos chilenos a emprender. Una de las mujeres nos comenta su situación de esta manera:

Estuve trabajando en un crucero (5 meses) antes de irme a Granada. Voy a cumplir un año en esto, pero ya cumplí 2 años en Graná y el primer año, como por así llamarlo, estuve trabajando en cualquier cosa: Desde intentando ser comercial a puerta fría de Endesa, Iberdrola y todas esas cosas, pasando por bares de tapas. Obviamente ninguno me daba de alta en la Seguridad Social, porque son así ahora. Y hasta que, bueno, ya después por empresas privadas, no sé, en maquillaje y después me metí en una empresa de turismo aquí. Ahí sí que no me gustó porque el dueño era un idiota y prefería estar sin trabajo que trabajar con él y de ahí me metí al tema de los apartamentos turísticos y dije "Bueno de aquí mientras no encuentre trabajo, me moveré con esto" y poco a poco si no te sale trabajo te vas motivando porque si seguís haciendo lo mismo todo el tiempo uno se aburre (Josefina, 28 años).

\section{Facilidades y obstáculos para emprender}

En términos generales, los chilenos poseen una visión positiva respecto de los negocios impulsados en Almería, así como de las relaciones comerciales y personales que establecen con sus habitantes. En un alto porcentaje (13/15) señalan no haberse sentido nunca discriminados por los españoles y, muicho más importante, consideran que son un buen aporte para la economía local. Algunos relatos nos dan cuenta de ello:

Bien, yo qué sé, siempre me he sentido cómodo la verdad, aquí en Almería nunca me he sentido discriminada..., yo qué sé, será porque la gente de aquí es así, pero siempre me han tratado bien, o sea, al contrario, ninguna queja. Quizás, quizás en el pueblo en Lucainena [pueblo del interior], sí. Sí porque siempre hay gente pues eso de pueblo, quizás un poquito más cerrada, qué sé yo, allí pues viven muchos abuelitos y gente mayor y que los fines de semana van los jóvenes para allá, pues siempre hay algún abuelo que dice, “¿oye y por qué no trabaja mi nieto que es de aquí?" Pero poco más (Diego, 27 años).

Es que es lo que te digo, yo siempre, siempre, siempre he tenido una acogida increíble, o sea con los españoles, nunca he sentido que alguien me hubiera dicho "Ah..., es que tú eres chilena, inmigrante"; o sea, a lo mejor me lo han dicho, pero de broma, ¿me entiendes? Y a lo mejor con los argentinos nos bromeamos unos a otros porque tenemos esa pulla [risas]. Nunca, nunca. O sea, muy bien (Marcela, 43 años).

Ha sido posible observar algunas experiencias aisladas de discriminación que se encuentran asociadas a rasgos físicos, también a la forma de vestir o de actuar de los emprendedores. Una mujer narra haber sufrido discriminación proveniente de un argentino, quien le dijo de manera despectiva que era una indígena, que se devolviera a su tierra. Josefina cuenta un episodio donde se sintió violentada:

Sí me pasó, cuando ayudé a una ex compañera de Play, granadina, le dije "Vente a trabajar conmigo en los apartamentos", cometí el error... Te comenté de este tío machista que fui a la entrevista y tal, que al final no me seleccionó, pues me llamó $p a$ hacer un trabajito de ayudarle con una limpieza de una casa, no sabíamos que la casa había estado ocupada durante 4 meses y estaba mal, y resulta de que esta chica cuando terminamos en el trabajo que no lo hicimos al $100 \%$ por las condiciones en que estaba la casa, este señor la llama y ella, en vez de decirle "Sí, sí, ya hablo con ella", le contestó: "Ya te lo dije que ella era sudaca, que era guarra, cómo confías en ella, deberías haber confiado en mí desde el comienzo...". Pues mira tú que yo, gracias a eso, perdí un trabajo, unos mil y pico euros perdidos, calculo (Josefina, 28 años).

Cuando les preguntamos a los participantes acerca de las facilidades para emprender sus negocios, la mayoría indicó que la recomendación 
entre clientes era su mejor carta de presentación para el desarrollo de sus actividades comerciales; así mismo destacan las asesorías, aunque en la mayoría de los casos han sido por cuenta propia y no obedecen a una política de acompañamiento en los negocios de personas inmigradas. Lo mismo ocurre con los equipos técnicos que apoyan los emprendimientos, estos no son provistos por los organismos locales, sino que son contratados por los emprendedores; por ejemplo, gestores o abogados que facilitan la gestión administrativa y financiera de los negocios. Una de las participantes cuestiona el sistema diciendo:

Ya es una cosa desproporcionada, ponen muchas trabas, muchas pegas para poder poner lo que es un negocio establecido legalmente como todos quisiéramos (Ángela, 46 años).

En opinión de nuestros informantes, a los españoles les asiste el sentimiento de que los extranjeros reciben más ayudas que ellos a la hora de emprender negocios, algo que les parece injusto, y que normalmente es falso. Al mismo tiempo, en sentido contrario, afloran los prejuicios asociados al estatus migratorio, donde los nativos suelen pensar que los latinos debieran ocuparse en tareas menos cualificadas.

Algunas de las entrevistas evidencian una cierta diferenciación por origen cultural que determina la forma en que los autóctonos se relacionan con los migrantes. Cecilia indica:

Yo creo que va todo en la confianza, porque cuando la gente ya te conoce, se abre y si te puede ayudar... te ayuda. A lo mejor con los latinos no hay tanto rechazo, porque como mezclados con los de acá... Porque, a ver, si miro en mi trabajo que yo desempeño, que la gente, los españoles, tienen su distancia, a veces mucha, con los marroquís o con los rumanos. Yo, por ejemplo, cuando yo he tenido un piso y le pregunto al propietario: “¿Qué perfil de cliente quiere?", él me dice: "Mire no me traigas ni moros, ni rumanos", ¡ni qué se yo cuántos más! Entonces, yo ahí sí veo un poquito de discriminación con esas personas. Tampoco quieren negros (Cecilia, 62 años).
Dentro de los obstáculos que son mencionados por los chilenos se encuentran la falta de cooperación con otros empresarios del mismo rubro, altos costos para implementar, créditos con intereses altos y la inestabilidad económica del país, como la crisis sufrida hace una década.

\section{Conclusiones}

Tras los datos obtenidos en nuestra investigación, analizados en las páginas que preceden, se vislumbran las siguientes conclusiones.

Respecto de las características socioeconómicas de la muestra se observa que las actividades desarrolladas con mayor frecuencia por los chilenos en Almería se relacionan con la prestación de servicios a personas (como el servicio a domicilio, servicios de limpieza, clases de pádel y de baile, tour privados o el cuidado de adultos) y empresas de corretaje de propiedades, administración de locutorios y la hostelería, en rubros de alimentación, restaurantes y cafeterías. Ciertamente un buen número de esta población inmigrada posee estudios superiores, pero sus opciones de emprendimiento distan bastante de lo que debería ser su profesión, según la formación alcanzada.

En segundo lugar, los emprendedores chilenos en Almería ya traían de origen experiencias de emprendimientos, gracias a los negocios familiares de los que son propietarios. Así se recoge en 8 de los 15 entrevistados. Por lo demás, en España hoy todos son dueños de sus negocios o sus propios jefes. Ello no es obstáculo para que, casi en tu totalidad, antes de emprender un negocio propio, cuando iniciaron su proyecto migratorio estuvieran obligados a trabajar por cuenta ajena.

Tercero, respecto del lugar donde desarrollan su trabajo, 9 de los 15 entrevistados cuentan con negocios ubicados en un local comercial, el resto realizan su actividad bien en su domicilio, bien en el domicilio de los clientes o en lugares previamente acordados, como puede ser la venta de joyas, las clases de baile o la atención de adultos mayores.

Cuarto, según la jornada laboral, su actividad la realizan sin horario determinado, la mayoría de ellos se fija una cantidad de horas diarias -entre 8 y 12- y establecen los días de descanso semanales, que casi siempre es uno, el 
domingo, dependiendo del tipo de negocio. Como es frecuente que la actividad la ejerzan sin empleados (solo 5 de ellos emplean a otras personas, en cafetería, restaurante y comercio), para ellos el horario laboral es mucho más exigente.

En cuanto a sus principales proveedores y clientes depende del negocio, pero en su mayoría son españoles, a excepción de aquellas personas que se dedican a la gestión turística, donde los grupos de alemanes e ingleses son los más interesados en contratar sus servicios.

Sexto, respecto de la cuantía de sus ingresos, se considera un promedio de $3.646,43 € / \mathrm{mes}$, muy por encima de la media nacional. La nota destacada que aumenta esta mediana proviene de los ingresos de quienes regentan cafeterías y restaurantes, que aseguran alcanzar entre los $15.000 €$ y $20.000 €$ al mes. Ahora bien, si eliminamos de la muestra a los dueños de estos negocios, el promedio de ingreso recibido por chilenos emprendedores en Almería supera en muy poco los $1.100 € / \mathrm{mes}$. Entran dentro de lo que se les denomina coloquialmente como mileuristas. Incluso ciertos informantes no superan el salario mínimo interprofesional, llegando solo a los $816 € / \mathrm{mes}$.

Séptimo, los gastos necesarios para desarrollar sus actividades se refieren a los básicos mensuales de agua, energía, alquiler, mercaderías o insumos para la oferta del servicio. El promedio es de $1.083 €$, exceptuando a quienes tienen que pagar a los empleados. Si eliminamos a todos estos últimos, el promedio de gasto mensual es de $591 €$. Teniendo en cuenta la media de ingresos expuesta en la conclusión sexta, se observa que el líquido dinerario que perciben es bastante escaso: un promedio mensual de $224 €$. Haciendo un ejercicio de valoración o éxito del proyecto migratorio de estas personas, parece evidente que no ha sido muy gratificante, en cuanto a ingresos se refiere. Compárese con el ingreso medio de las personas empleadas en Chile (a 31/12/2016), que es de $467 € / m e s$ (según el INE, y la conversión de pesos a euros).

El segundo gran objetivo de esta investigación busca conocer la integración de los chilenos en el mercado laboral (en este caso por cuenta propia). El estudio nos deja con claridad, octavo punto de las conclusiones, que en España estos inmigrados cuentan con redes de apoyo estables (en su mayoría familiares), factor determinante para impulsar negocios propios, pues casi ninguno ha recibido ayudas públicas. Y, como adelantamos en la conclusión segunda, todos los participantes valoran su experiencia previa como un activo fundamental a la hora de permanecer en sus negocios, soportando, por ejemplo, los malos momentos de crisis.

Además, noveno, como buen indicador de integración social, se señala que la mayoría de los chilenos sienten no haber sufrido ninguna discriminación personal ni racismo, al margen de ciertos obstáculos de comunicación. Debe ayudar el hecho de ser trabajadores autónomos, pues los españoles aún señalan que los inmigrantes debieran ocuparse exclusivamente en los trabajos menos cualificados.

Finalmente, no son desdeñables las dificultades iniciales a la hora de llevar a cabo la instalación de ciertos negocios, sobre todo por las restricciones que impone la administración local a la hora de aprobar los permisos. Al margen quedan los costos de instalación y los intereses bancarios en sus créditos, en caso de préstamos, y la inestabilidad económica que ha vivido España en la última década. Sin embargo, los chilenos aseguran que sus emprendimientos o negocios han sido posibles y se han mantenido gracias a su credibilidad de empresarios y a la fidelidad conseguida con sus clientes. Experiencia acumulada en Chile y España. La mayoría los califican de exitosos, en espera de mejorarlos.

Ahora bien, el presente artículo también presenta algunas limitaciones detectadas: la principal es que se identifica como un estudio referido a la colonia de chilenos asentada en un lugar español muy concreto, Almería, por lo que sus resultados y conclusiones alcanzadas no pueden ser, categóricamente, transferibles a otras zonas, sobre todo si carecemos de estudios que lo corroboraran.

Por otro lado, mencionar que este artículo es fruto de un estudio más amplio en el que se están analizando también los resultados del emprendimiento de españoles asentados en las regiones chilenas del Maule y del Biobío. Sin duda alguna, los resultados finales no ofrecerán los datos suficientes para llevar a cabo una comparativa de los comportamientos socioeconómicos de chilenos en España y españoles en Chile. 


\section{Referencias}

Achidi Ndofor, H., y Priem, R. L.

2011 Immigrant entrepreneurs, the ethnic enclave strategy, and venture performance. Journal of Management, 37 (3), 790-818.

Arias, F.

2012 El proyecto de investigación, introducción a la metoArjona, A. dología científica. Caracas: Editorial Epistense.

2004 Inmigración y mercado de trabajo. El caso de la economía étnica en Almería. Tesis doctoral, Departamento de Ciencias Humanas y Sociales, Facultad de Humanidades y Ciencias de la Educación, Universidad de Almería.

Arjona, A.; Checa, F. y otros

2007 La economía étnica en el mercado de trabajo almeriense. Sevilla: Consejería de Gobernación. Junta de Andalucía.

Bravo, G.

2015 Las migraciones internacionales y la seguridad multidimensional en tiempos de la globalización. Revista Diálogo Andino, 48, 139-149.

Chaganti, R., y Greene, P. G.

2002 Who are ethnic entrepreneurs? A study of entrepreneurs apos; ethnic involvement and business characteristics. Journal of Small Business Management, 40 (2), 126-143.

Chand, M. y Ghorbani, M.

2011 National culture, networks and ethnic entrepreneurship: A comparison of the Indian and Chinese immigrants in the US. International Business Review, 20 (6), 593-606.

Checa, F.

1995 Migración, riesgo y beneficios. Los inmigrantes africanos en la provincia de Almería. Demófilo: Revista de cultura tradicional, 15, 103-134.

Checa, F.; Checa, JC. y Arjona, A.

2002 Las historias de vida como técnica de acercamiento a la realidad social. El caso de las migraciones. Las migraciones a debate: de las teorías a las prácticas sociales, en F. Checa (edit.). Barcelona: Icaria, 347-383.

Constant, A., y Shachmurove, Y.

2006 Entrepreneurial ventures and wage differentials between Germans and immigrants. International Journal of Manpower, 27 (3), 208-229.
Cornejo, J.; Sanhueza, S., y Rioseco, M.

2012 Orientaciones para la elaboración de tesis, seminarios y paper académicos. Talca: Universidad Católica del Maule.

Fairlie, R. W., y Meyer, B. D.

1996 Ethnic and racial self-employment differences and possible explanations. Journal of Human Resources, 31, 757-793.

Instituto Nacional de Estadística, Chile

2016 URL http://www.ine.cl/

Newland, K., y Tanaka, H.

2010 Mobilizing diaspora entrepreneurship for development. Washington DC: Migration Policy Institute.

Raijman, R., y Tienda, M.

2003. Ethnic foundations of economic transactions: Mexican and Korean immigrant entrepreneurs in Chicago. Ethnic y racial studies, 26 (5), 783-801.

Sanhueza, S.; Friz M., y Quintriqueo, S.

2017 Triangulación de métodos como propuesta para el estudio de competencia comunicativa intercultural en contextos de inmigración e interculturalidad. Andamios, vol. 14 (34), 283-303.

Sanhueza, S.; Penalva, C., y Friz, M.

2013 Identidades y competencias profesionales de estudiantes para maestro de educación infantil relativas a la enseñanza de la geometría. Revista Latinoamericana de Investigación en Matemática Educativa, 16 (1), 99-122.

Sasse, G., y Thielemann, E.

2005 A research agenda for the study of migrants and minorities in Europe. Article in JCMS Journal of Common Market Studies, 43 (4): 655-671.

Tovar, L. M., y Victoria, M. T.

2013 Migración internacional de retorno y emprendimiento: revisión de la literatura. Revista de Economía Institucional, 15 (29), 41-65.

Wong, L., y Primecz, H.

2011 Chinese migrant entrepreneurs in Budapest: changing entrepreneurial effects and forms. Journal of Asia Business Studies, 5 (1), 61-76.

Yuengert, A. M.

1995 Testing hypotheses of immigrant self-employment. Journal of Human Resources, 30 (1), 194-204. 